\title{
Climate Change and Urban Grass Land Soil Moisture Conditions in South-Western Ontario, Canada
}

\author{
S. Nishat ${ }^{*}$ Y. Guo, and B.W. Baetz \\ Department of Civil Engineering, McMaster University, Hamilton, ON L8S 4L8, Canada
}

Received 24 December 2007; revised 5 March 2007; accepted 24 March 2008; published online 1 December 2008

\begin{abstract}
Using the past 45 years of climate data in south-western Ontario, Canada and a deterministic continuous simulation model, this study investigates the long-term variability in rain-fed soil moisture in urban areas as influenced by climate change. Statistical analyses of four variables, i.e., soil moisture, precipitation, temperature and evapotranspiration were carried out. As found from other studies for other locations, these analyses confirm increasing temperatures and average growing season precipitation in south-western Ontario. Results show that both overall soil moisture and evapotranspiration have increased throughout the 45-year period. The probability/frequency distributions of soil moisture were obtained and the analysis shows an increasing average growing season soil moisture availability from the 1960's to the 1990's. The direct influence of precipitation and temperature on soil moisture and evapotranspiration were examined, revealing a stronger relationship of soil moisture and evapotranspiration with precipitation rather than temperature. Overall increasing average growing season soil moistures have very likely resulted from overall increasing rainfall during the growing seasons in south-western Ontario.
\end{abstract}

Keywords: temperature, precipitation, evapotranspiration, continuous simulation, frequency distributions

\section{Introduction}

Studies have successfully shown that during the latter part of the $20^{\text {th }}$ century an increase in sulphate aerosol and green house gas concentrations has resulted in not only increased temperatures (Chen, 2007; Dang et al., 2007; Vinnikov and Grody, 2003; Easterling et al., 2000; Whitfield and Cannon, 2000; Mavromatis and Jones, 1999) but also higher annual precipitations (Groisman et al., 2005; Changnon and Westcott, 2002; Easterling et al., 1999; Kunkel et al., 1999; Angel and Huff, 1997). Changes in temperature characteristics have been identified as higher minimum temperatures more than higher maximum temperatures (Hamlet et al., 2007; Wilby et al., 2002; Easterling et al., 2000; Zhang et al., 2000) and also higher average winter temperatures (Trenberth, 1999; Lewis, 1989). As the temperature increases, the moisture holding ability of the near-surface atmosphere also increases, resulting in the possibility of higher magnitude rainfall events (Trenberth, 1999). For regions of Canada, it was established that annual precipitation has increased during the latter part of the $20^{\text {th }}$ century (Wilby et al., 2002; Easterling et al., 2000; Stone et al., 2000; Zhang et al., 2000). According to Trenberth (1999), there is firm evidence that atmospheric moisture has increased. Studies have shown that there are higher heavy $(\geq 50.8 \mathrm{~mm} /$

\footnotetext{
* Corresponding author. Tel.: +1 905 8210345; fax: +1 9055299688.

E-mail address: nishats@univmail.cis.mcmaster.ca (S. Nishat).
}

ISSN: $1726-2135$ print/1684-8799 online

(C) 2008 ISEIS All rights reserved. doi:10.3808/jei.200800129 day) rainfall events (Groisman et al., 2005; Kunkel et al., 2003; Changnon and Westcott, 2002; Easterling et al., 2000; Karl et al., 1995) and that there is a decline in moderate (12.7 $\sim 25.4 \mathrm{~mm} /$ day $)$ and light $(2.54 \sim 12.7 \mathrm{~mm} /$ day $)$ precipitation events and also an increase in the frequency of occurrence of dry days (Trenberth, 1999; Karl et al., 1995; Smit, 1989). The detailed characteristics of this increase in heavy rainfall events depend on geographic locations. For example, in the UK, heavy precipitation events have increased in winter and decreased in summer (Fowler and Kilsby, 2003; Osborn et al., 2000; Mitchell and Warrilow, 1987). In contrast, increasing trends of heavy precipitation in the US (except the West Coast) and Southern and Eastern Canada for springs and summers were observed (Stone et al., 2000; Kunkel et al., 1999; Groisman and Easterling, 1994; Lewis, 1989).

Nemec and Schaake (1982) predicted that the most prominent effect of global warming is that snowmelt will increase and sea levels will rise. The other concerns include decreasing availability of plant water (Varanou et al., 2002; Mavromatis and Jones, 1999; Zweirs and Kharin, 1997; Smit, 1989), increase in non-point source pollution (Chen et al., 2007; Tong et al., 2007), and anomalies in vegetal patterns (Dang et al., 2007, Manobavan et al., 2003; Lewis, 1989; Smit, 1989). Knowledge of the impact of climate change on vegetation is limited (Manobavan et al., 2003; Smit, 1989). In their study, Dang et al. (2007) investigated the influence of global warming on seven vegetal land-use groups ranging from tropical forests to bare soils. They have shown that the most significant influence was during 1950 to 2004. Porporato et al. (2004) 
examined the impact of rainfall amounts and frequency on grasslands in arid regions. Their study showed that decreasing total rainfall amounts and frequency have a great impact on leaf carbon assimilation. Smit (1989) predicted that climate change will affect forestry more than agriculture due to the longer growing cycle of trees allowing less adaptability. Other studies have predicted that at the current increasing rate, grasslands will replace the rainforests (Dang et al., 2007). It has been predicted that in south-western Ontario and nearby US states, there is a possibility of reduced yields of many crops due to the expected deficits of available soil moisture coupled with temperature increases (Smit, 1989). Mavromatis and Jones (1999) used an atmosphere-ocean General Circulation Model (GCM) to simulate future temperature and precipitation and predicted decreasing yields in 2011 to 2099 due to decreasing soil moistures and increasing evapotranspiration (ET), as winter temperatures will continue to increase. It is therefore paramount to study the response of soil moisture to global climate change, especially in the agricultural sector.

As mentioned in various studies, long-term soil moisture data is not readily available (Nishat et al., 2007; Guo and Dirmeyer, 2006; Hirabayashi et al., 2005; Maurer et al., 2002; Entin et al., 1999; Wang and Kumar, 1998). Only in recent years a few soil moisture databases have been established. Soil moisture data sets are now available for the Former Soviet Union (FSU), Illinois, USA and China (Guo et al., 2006; Srinivasan et al., 2000). Robock et al. (2000) have created a Global Soil Moisture Data Bank (GSMDB) with soil moisture data from over 600 stations across India, China, the US and Mongolia. The GSMDB was identified as the most complete collection of long term global soil moisture data by Guo and Dirmeyer (2006). However, not all GSMDB stations have complete data coverage for the time span of interest (Guo et al., 2006). Another long-term soil moisture data set $(1950 \sim 2000)$ is that of Maurer et al. (2002). Mahmood and Hubbard (2003, 2004) described the preparation of a data set (from 1982) for soils and soil moisture from $150 \sim 200$ sites. A long-term (since 1957) data set from 35 stations across the Canadian Prairies is available from Saskatchewan and Southern Manitoba (Wittrock and Ripley, 1999). Unfortunately, these data sets are limited to a few locations and significant differences exist between locations. Therefore, simulation models are still the best tool available to examine soil moisture conditions for many locations of interest. The dependency of soil moisture on climate conditions has always been the center of many investigations and even more so now with our changing climate.

\section{The Climate and Soil Moisture}

The availability of soil moisture depends on the climate as precipitation is the principal source of soil moisture and surface temperature, relative humidity, wind speed and solar radiation etc. influence the loss of soil moisture via ET. Increasing temperatures will result in an increase in ET (Hamlet et al., 2007; Smit, 1989; Nemec and Schaake, 1982). ET is also closely related to precipitation (Mahmood and Hubbard, 2003; Liang et al., 1994) and soil moisture (Hamlet et al., 2007; Srinivasan et al., 2000). China and North America have witnessed increasing magnitudes in relative humidity due to climate change (Easterling et al., 1999). Changes in temperatures have also resulted in changes in wind speeds (Zwiers and Kharin, 1997; Lewis, 1989). Many have projected that increase in precipitation is small compared to the increase in ET due to increasing temperatures (Lewis, 1989). For example, in the warmer parts of the world soil moisture availability has decreased even with increasing precipitation (Easterling et al., 2000; Zwiers and Kharin, 1997). In parts of Asia, Africa, and North America, there has been a decrease in soil moisture due to increasing temperatures (Easterling et al., 2000). Whereas Sridhar et al. (2006) found from their six year study that annual ET never exceeds annual precipitation. Interestingly, higher average winter temperatures have resulted in more precipitation than snowfall (Lewis, 1989), allowing an increase in Surface Runoff (Hamlet et al., 2007) and soil moisture (Trenberth, 1999). Surface Runoff (SR) has increased in various parts of the world due to an increase in precipitation frequencies (Hirabayashi et al., 2005; Angel and Huff, 1997). Other studies have found an increase in summer growing season soil moisture due to increasing summer rainfall (Hirabayashi et al., 2005; Mahmood and Hubbard, 2004; Wittrock and Ripley, 1999).

The strong relation between climate characteristics and long-term soil moisture has been demonstrated in many studies. Guo et al. (2006) showed a strong influence of radiation on soil moisture. Research illustrated that soil moisture availability is temperature dominated (Zhang et al., 1999; Wang and Kumar, 1998). Time series studies of precipitation and soil moisture have demonstrated a strong relationship between the two (Guo et al., 2006; Mahmood and Hubbard, 2003; Srinivasan et al., 2000; Zhang et al., 1999; Mitchell and Warrilow, 1987). Varanou et al. (2002) used GCM to simulate future climate characteristics and predicted, using the SWAT model, decreasing soil moisture and SR due to decreasing summer precipitation in Central Greece in the year 2050. Robock et al. (2000) analyzed soil moisture data of more than 15 years from over 600 stations located all over the world under grasslands and agricultural land uses. They concluded that soil moisture availability has increased as, contrary to popular belief, increasing precipitation compensates for increasing ET due to increasing temperatures. In their study of 100 years of soil moisture from various parts of the globe, Hirabayashi et al. (2005) support Robock et al. (2000) in that soil moisture levels have gone up.

Many studies have shown that soil moisture in return is an excellent predictor of surface temperature and precipitation (Guo et al., 2006; Robock et al., 2000; Wang and Kumar, 1998). Soil moisture is an important component in the climate system (Douville and Chauvin, 2000; Mintz and Walker, 1993) as it influences surface heat fluxes, surface temperatures (Guo and Dirmeyer, 2006; Srinivasan et al., 2000; Robock et al., 1998; Huang et al., 1996) and precipitation (Guo and Dirmeyer, 2006; Hirabayashi et al., 2003; Srinivasan et al., 2000). GCMs widely used in predicting future temperature and precipitation patterns require information of soil moisture for accurate simulation (Guo and Dirmeyer, 2006; Hirabayashi et al., 2003; Douville and Chauvin, 2000). The purpose of this study is to 
identify the temporal patterns of growing season soil moisture in the urban areas of south-western Ontario, Canada, and to investigate the influence of climate on long-term soil moisture characteristics under urban land-use.

\section{Materials and Methods}

\subsection{The Model}

The water balance model developed by Nishat et al. (2007) was used to simulate soil moisture in the root zone throughout the growing season (May to October). The soil water balance model, schematically represented by Equation (1), is one-dimensional, taking into account only the hydrological processes that operate in the vertical direction. The model represents the soil domain as a single homogeneous layer. The model simulates soil moisture at a point, and the output of the model can be viewed as area/site-averaged values as the inputs are all area/site-averaged values. The model was validated and its performance was evaluated with observed field data (Nishat et al., 2007):

$$
n Z r \frac{d s(t)}{d t}=P(t)-S R(t)-E T(s)-L(s)
$$

where:

$s=$ Volumetric Soil Moisture content in $\mathrm{cm}^{3} / \mathrm{cm}^{3}$;

$\mathrm{Zr}=$ Depth within the soil root zone in $\mathrm{cm}$;

$n=$ Porosity;

$P=$ Precipitation in $\mathrm{cm} /$ day;

$E T=$ Evapotranspiration in $\mathrm{cm} /$ day;

$S R=$ Surface runoff in $\mathrm{cm} /$ day;

$L=$ Deep Percolation in $\mathrm{cm} /$ day; and

$t=$ Time index with an interval length of one day.

This continuous simulation model incorporates the wellestablished models of each of the individual processes that take part in the water-balance. SR is estimated using the US National Resources Conservation Services (NRCS) curve number technique. This SR component was modified from that of Nishat et al. (2007) to better represent urban land-use. Very heavy precipitation events were given special attention. Very heavy precipitation events will likely result in even the pervious areas to function as impervious. The soil may become fully saturated allowing more SR to take place. As the NRCS curve number technique models SR based on pre-existing soil conditions, i.e., dry conditions, average conditions and wet conditions, it was taken into consideration that high precipitation days should fall into the wet condition criteria. It is assumed that precipitation events greater than 2 inches $(5 \mathrm{~cm})$ fall into the very heavy precipitation category. Potential Evapotranspiration (PET) is estimated using Penman's Method. Actual Evapotranspiration (AET) is then modelled from PET as a function of soil moisture and is further adjusted to represent various plant growth stages. Plant growth stages are represented by Leaf Area Index (LAI). Leakage is modelled as vertical per- colation and as a function of soil moisture. The AET and leakage calculation procedures included in this model emphasize the soil moisture regime's control over these two processes, and is different from the way other deterministic models represent these two processes within the water balance. Equation (1) is solved numerically by using the backward finite difference method. Detailed description of the continuous simulation model is provided in Nishat et al. (2007).

\subsection{The Study Area and Data}

The study area is not an actual site but hypothetical urban lands adjacent to the Toronto Pearson International Airport

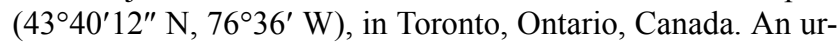
ban area is comprised of both pervious and impervious parts. Pervious areas may be covered by natural vegetation or open soils and impervious areas are covered by roads and buildings. Two scenarios were examined in this study. For the first scenario, it was assumed that a piece of land represented by the point scale model is completely covered with grass. This scenario is representative of large open spaces in urban areas. The second scenario represents a composite land use with the existence of both grass cover (pervious) and impervious areas. The second scenario is representative of average residential neighbourhoods where impervious and pervious areas are intertwined. In this study, scenario 2 considers a specific case with $70 \%$ vegetation and $30 \%$ impervious area. The processes that are directly influenced by this composite land-use are SR, ET, and leakage. For $\mathrm{SR}$ a $\mathrm{CN}_{2}$ that represents $70 \%$ vegetation and $30 \%$ impervious area is used to represent this composite landuse. To model ET and leakage properly over composite areas, the ET and leakage module of the point scale model were modified. PET was still determined using Penman's method. PET was then partitioned between Transpiration and Evaporation using LAI. For scenario 2, LAI was reduced by $30 \%$ from that of $100 \%$ grass cover. Similarly, leakage is first modeled the same as in scenario 1 and then reduced by $30 \%$ as percolation will not occur over the impervious portion.

It is noted the methodology used here simplifies the hydrological cycle over urban areas. However, the major influential factors are considered because the main focus is to understand better the long-term fluctuations of soil moisture. By modeling the two scenarios, it is hoped that average conditions in urban areas are well represented. The study period is from 1960 to 2004. Climate data including precipitation, temperature, solar radiation, relative humidity, and wind speed were collected from the Ontario Climate Centre (station No. 6158733, Toronto Pearson Airport). The original data are hourly values, daily totals or averages were calculated from the hourly values. There were very few missing data, and the missing data were replaced with data from an adjacent weather station (St. No. 6158350). The growing season at this location was identified as from May to October. The climate here is humid continental with warm humid summers and fairly low diurnal temperatures. Average annual precipitation is $83 \mathrm{~cm}$. Summer is the wettest season, with the bulk of rainfall falling during thunderstorms. Soil characteristics were available from Hoffman 

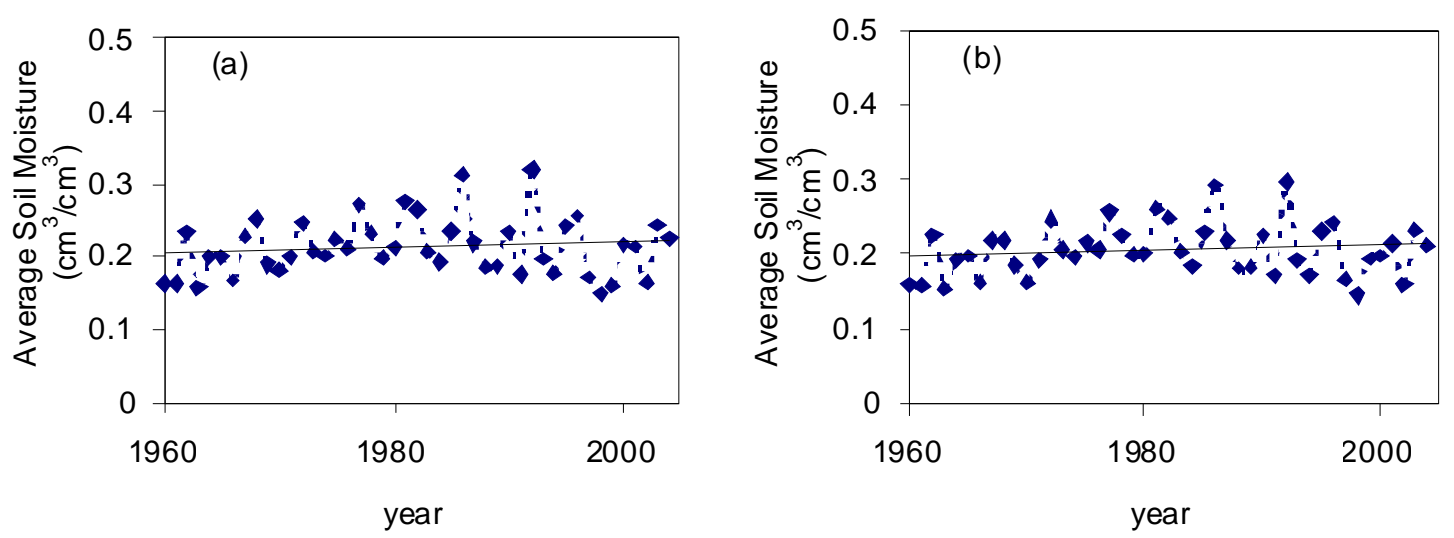

Figure 1. Model-simulated average growing season soil moisture for 1960-2004 (a) scenario 1 and (b) scenario 2.

and Richards (1953). Coarse textured sandy loam soils dominate the top $30 \sim 40 \mathrm{~cm}$, followed by medium textured loam soils, with the last $30 \sim 40 \mathrm{~cm}$ of fine textured clay loam soils followed by clay soils. Soil moisture is simulated for rooting depths of $30 \mathrm{~cm}$, which is typical for grass lands. At this depth the soil type is sandy loam. The input data used for the model are summarized in Table 1.

Table 1. Soil, Plant and Climate Parameters Used as Input for the Continuous Simulation of Growing Season Soil Moisture under Urban Land-use

\begin{tabular}{llll}
\hline Parameters & Input Values & Parameters & Input Values \\
\hline$\Lambda$ & $5-17 \%$ & $\mathrm{n}$ & 0.434 \\
$\mathrm{~K}_{\mathrm{s}}$ & $86.4 \mathrm{~cm} /$ day & $\mathrm{s}^{*}$ & 0.55 \\
$\mathrm{~b}$ & 4.9 & $\mathrm{~s}_{\mathrm{w}}$ & 0.26 \\
$\psi_{\mathrm{s}}$ & $21.8 \mathrm{~cm}$ & $\mathrm{~s}_{\mathrm{h}}$ & 0.11 \\
\hline
\end{tabular}

In Table $1, \mathrm{n}$ represents porosity and $\Lambda$ rainfall interception. $\mathrm{K}_{\mathrm{s}}$ is the saturated hydraulic conductivity required for calculating leakage. $\bar{\psi}_{\mathrm{s}}$ and b are empirically determined parameters required for obtaining soil moisture control criteria at no water stress, $\mathrm{s}^{*}$, permanent wilting point, $\mathrm{s}_{\mathrm{w}}$, and hygroscopic point, $s_{\mathrm{h}}$. The values of $\mathrm{s}^{*}, \mathrm{~s}_{\mathrm{w}}$ and $\mathrm{s}_{\mathrm{h}}$ were calculated with the soil water potentials of $\psi_{\mathrm{s}, \mathrm{s}^{*}}=-30 \mathrm{kPa}, \psi_{\mathrm{s}, \mathrm{sw}}=-1500 \mathrm{kPa}$, and $\psi_{\mathrm{s}, \mathrm{sh}}=-10^{6} \mathrm{kPa}$ respectively. From the curve number tables of Chow et al. (1988) and Viessman and Lewis (2003), $\mathrm{CN}_{2}$ was taken as 61 for scenario 1 and 72 for scenario 2. For scenario 2, this is the average of the $\mathrm{CN}_{2}$ values for residential areas of $1 / 4,1 / 3$ and $1 / 2$ acres. The $\mathrm{CN}_{2}=72$ was computed assuming that the runoff from the house and driveway is directed to- wards the street with a minimum of roof water directed to the lawn (Chow et al., 1988).

This is often seen in practice although the current Ontario stormwater management policy encourages directing house and driveway runoff to lawns. Values of LAI needed to represent plant growth stages were varied between 0.2 to 0.9 $\mathrm{m}^{2} / \mathrm{m}^{2}$ throughout the growing season. The sources of these input data values and other data necessary to run the model that could not be shown here due to space limitations can be found in Nishat et al. (2007).

\section{Results and Discussions}

Driven by the required climate data input, the model was run for each individual growing season from 1960 to 2004 for the two scenarios. Daily SR, ET, leakage and soil moisture etc. were calculated for each year. In order to represent long-term soil moisture characteristics in a concise way, various statistical calculations were performed using the simulated time series. For example, taking the average of May $1^{\text {st }} 1960$, May $1^{\text {st }}$ 1961 , May $1^{\text {st }} 1962$, etc. will determine the typical May $1^{\text {st }}$ characteristics for the 45 year time series.

\subsection{Soil Moisture}

From the simulated daily soil moisture for each growing season $(1960 \sim 2004)$, the average soil moisture for each individual year was obtained. The graphical representation of the 45 year average growing season soil moisture time series as simulated by the continuous simulation model is presented in Figure 1.

Simulation results from scenario 1 are most representative of large open spaces (e.g. parks, baseball fields etc.) where soil moisture is not affected by nearby roads and buildings. Whereas those from scenario 2 are most representative of average neighbourhoods or commercial districts where soil moisture is affected by both the soils at the point and nearby impervious areas. The two sets of results can give us an idea of soil moisture behaviours in urban areas. Simulation of the two scenarios is necessary, given the point nature (i.e., only the vertical components of the water balance are considered) of the model. Interannual growing season soil moisture variability is evident from Figure 1. A linear regression line was fitted to the simulated time series. It is evident from this trend line that there has been a slight increase in overall growing season soil moisture for both scenarios, since 1960, despite the fluctuations from one year to the next. The Standard Deviations (SD) and the Coefficients of Variation (COV) of the daily soil moisture values for each growing season were calculated. The results are presented in Figure 2.

From Figure 2(a) and 2(b), we see that there has been a slight increase in the SD values from 1960 to 2004, which 

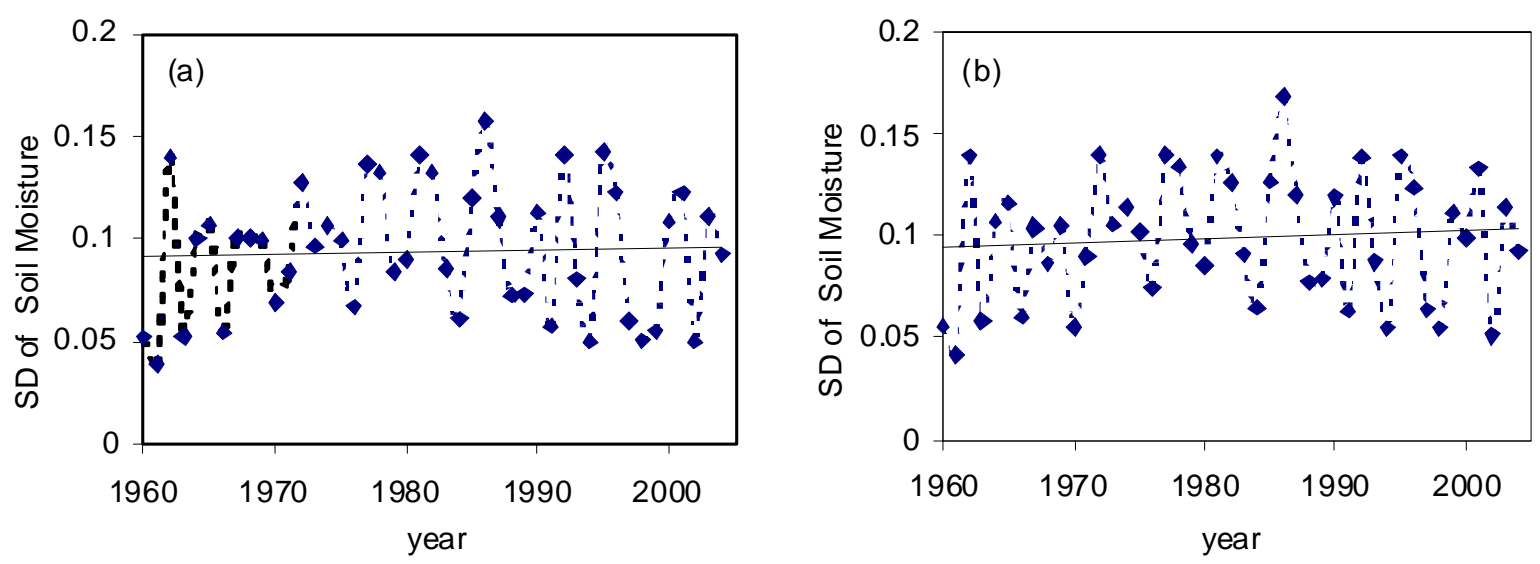

Figure 2. The standard deviations of the simulated growing season soil moisture from 1960 to 2004 (a) scenario 1 and (b) scenario 2 .
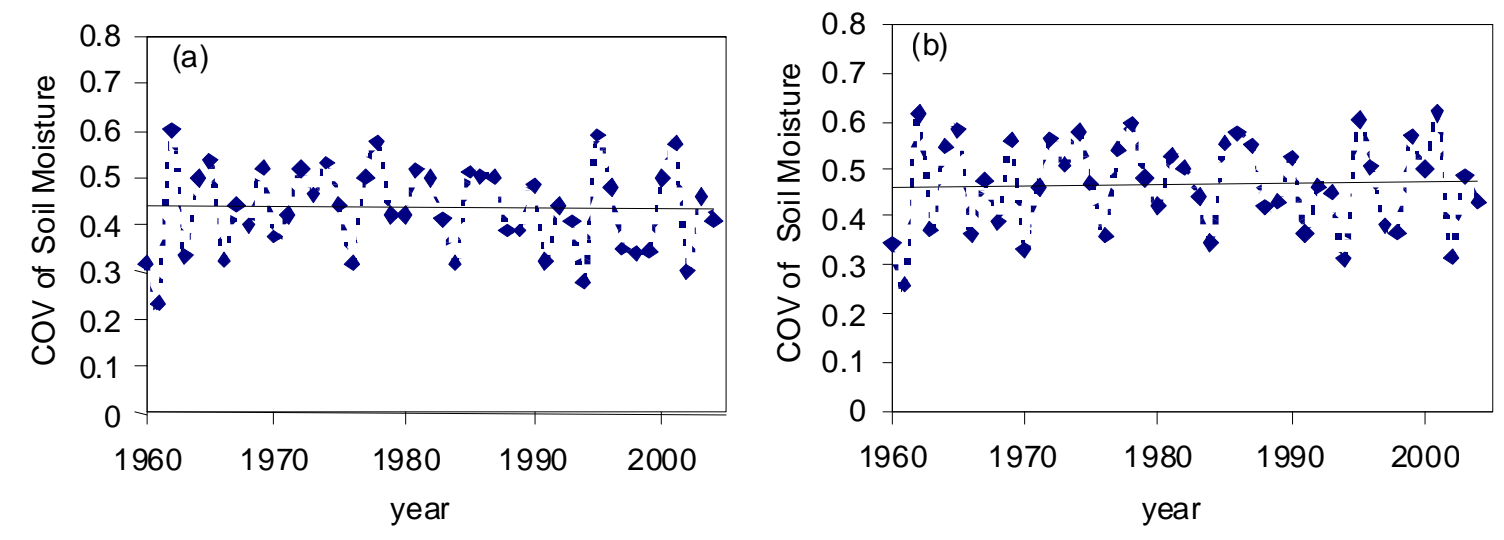

Figure 3. The coefficients of variation of the simulated growing season soil moisture from 1960 to 2004 (a) scenario 1 and (b) scenario 2 .

means that the day to day variation of soil moisture has steadily increased from the 1960's to 2004. The COV of the soil moisture time series were calculated for each individual growing season as well. These results are presented in Figure 3.

Figures 3(a) and 3(b) shows that the inter-annual COV vary widely $(0.2 \sim 0.6)$ from one another and the linear regression line indicates that there is no significant increase or decrease from 1960 to 2004 . The fact the COV neither increases nor decreases is a result of slightly increased average growing season soil moisture accompanied by increased standard deviation of daily soil moistures in each growing season. To better detect any possible changes in soil moisture, the simulated soil moisture time series was divided into to equal parts, 1960 1981 and $1982 \sim 2003$ each consisting of 22 years. Given our interest in the degree of fluctuation of soil moisture due to climate change, the probability/frequency distributions (pdf) of soil moisture during the two 22 year periods were obtained. The pdfs are presented in Figures 4(a) and 4(b).

The pdfs clearly indicate that there has been a shift to the right, indicating the more likelihood of occurrence of higher soil moistures. The $1960 \sim 1981$ pdf is unimodal, indicating the dominance of soil moisture at $0.2 \mathrm{~cm}^{3} / \mathrm{cm}^{3}$. Whereas, the $1982 \sim 2003$ pdf is bimodal, indicating the dominant peak at $0.2 \mathrm{~cm}^{3} / \mathrm{cm}^{3}$ and a second less dominant peak at $0.3 \mathrm{~cm}^{3} / \mathrm{cm}^{3}$. It is evident from Figure 4 that $0.2 \mathrm{~cm}^{3} / \mathrm{cm}^{3}$ is still the most common amount of soil moisture likely to exist throughout the growing season (May to October). However, in recent years there is an increased probability that soil moistures may attain a higher value of $0.3 \mathrm{~cm}^{3} / \mathrm{cm}^{3}$. There is a significant difference noticeable between Figures 4(a) and 4(b). When 30\% imperviousness is taken into consideration, i.e., Scenario 2, the possibility of the existence of higher soil moistures is less than that of complete grass cover, i.e., Scenario 1. This is because more water is lost through SR in scenario 2.

Soil moisture characteristics per decade in response to global warming were investigated by splitting the entire 45 year time-series into individual decades. The four decades of the 60's, 70's, 80's and 90's were separated and analyzed. The probability/frequency distributions of the four decades of soil moisture values were obtained and are presented in Figures 5(a) and 5(b).

The comparison clearly shows that there has been a shift 

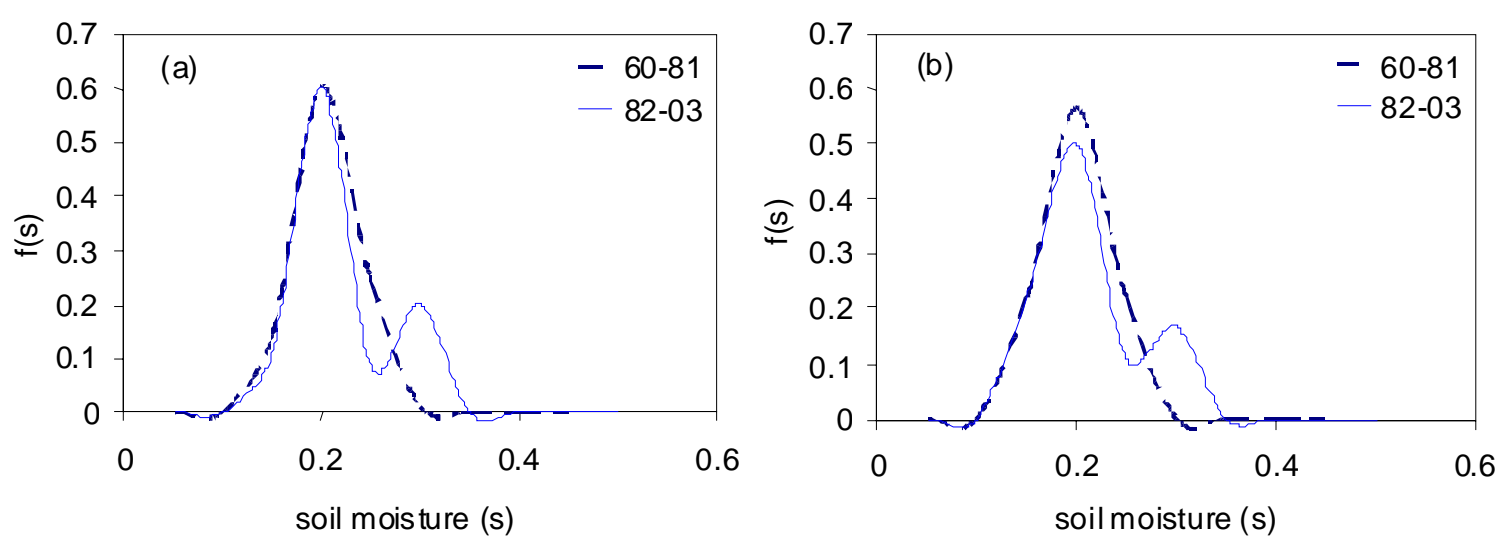

Figure 4. The probability density functions of the growing season soil moisture for the two time periods of 1960-1981 and 1982-2003 (a) scenario 1 and (b) scenario 2.
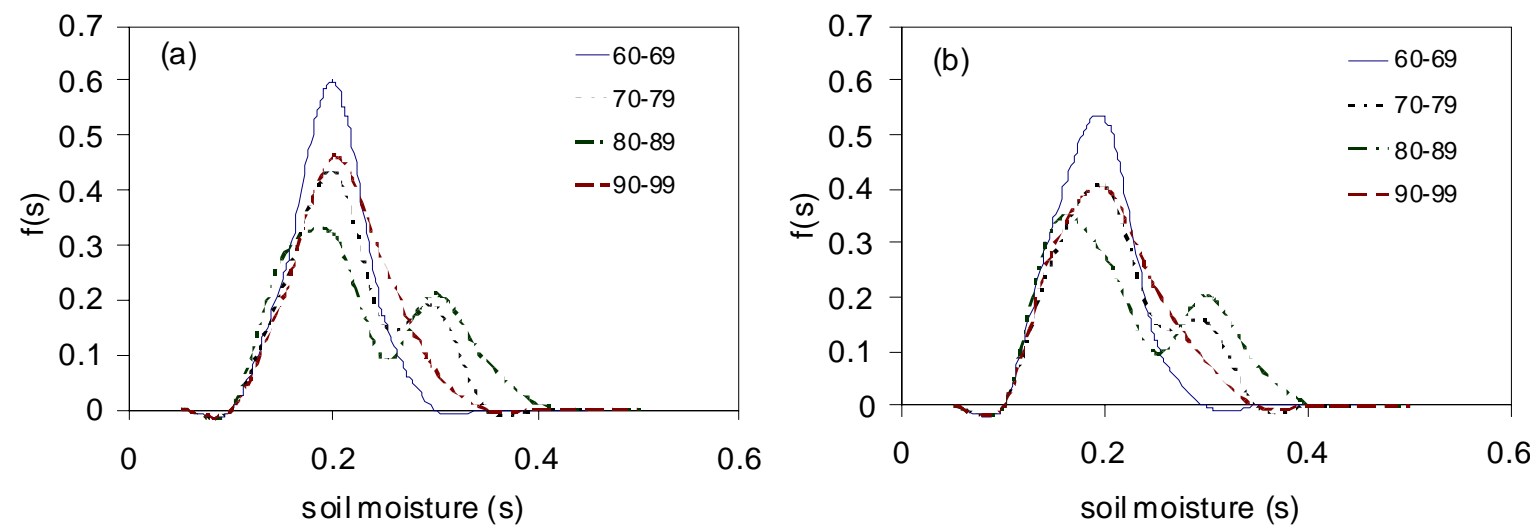

Figure 5. The probability density functions of the growing season soil moisture for the time periods of 1960-1969, 1970-1979, 1980-1989 and 1990-1999 (a) scenario 1 and (b) scenario 2.

to the right, again indicating the more likelihood of occurrence of higher soil moistures. The $1960 \sim 1969$ pdf for both scenarios is unimodal, indicating the dominance of soil moisture at 0.2 $\mathrm{cm}^{3} / \mathrm{cm}^{3}$. The most significant difference between decades is that between the 60's and the 70's. The $1970 \sim 1979$ pdf for scenario 1 is clearly bimodal, indicating the dominant peak at $0.2 \mathrm{~cm}^{3} / \mathrm{cm}^{3}$ and a second less dominant peak at $0.3 \mathrm{~cm}^{3} / \mathrm{cm}^{3}$. For scenario 2 , the $1970 \sim 1979$ pdf is similar to that of scenario 1 only that the higher soil moisture peak is less defined. The bimodal trend continues in the following decade of 1980 $\sim 1989$, having again two peaks at 0.2 and $0.3 \mathrm{~cm}^{3} / \mathrm{cm}^{3}$. The overall distribution of $1970 \sim 1979$ and $1980 \sim 1989$ pdfs are similar to each other however, the dominant peak in the 1980's pdf attains a smaller value than that in the 1970's and in the third decade for scenario 1, the falling limb is less steeper than that from the previous decade, indicating the higher probability of attaining higher moisture levels. The $1990 \sim 1999$ pdf for both scenarios is also unimodal, again indicating the dominance of soil moisture at $0.2 \mathrm{~cm}^{3} / \mathrm{cm}^{3}$. However, the falling limb ends near the $0.35 \mathrm{~cm}^{3} / \mathrm{cm}^{3}$ mark. The pdfs also show that the probability of soil moisture amounts near $0.4 \mathrm{~cm}^{3} / \mathrm{cm}^{3}$ no longer exists in the 1990s. Figure 5 confirms that $0.2 \mathrm{~cm}^{3} / \mathrm{cm}^{3}$ is the most common amount of soil moisture likely to exist throughout the growing season and the increasing trend of soil moisture shown in the 1970 s and 1980s does not seem to continue into the $1990 \mathrm{~s}$.

\subsection{Precipitation}

The precipitation characteristics of each individual growing season $(1960 \sim 2004)$ were analyzed. The total growing season precipitation as well as the average daily growing season precipitation were calculated. The results are shown in Figures 6(a) and 6(b). Figure 6 clearly shows the year to year fluctuations in growing season precipitation. As can be seen from Figure 6 , linear regression analysis was carried out and it shows that there has been a steady increase in growing season precipitation from 1960 to 2004 . Similar to the soil moisture analysis, the precipitation time series was divided into the two sets of $1960 \sim 1981$ and $1982 \sim 2003$. The means, the SD, and the COV of the two sets were calculated and are shown in Table 2.

There has been a $4.6 \%$ increase in average growing season precipitation in the 22 year period of $1982 \sim 2003$ from that of $1960 \sim 1981$. What is interesting from Table 2 is that, even though precipitation amounts have increased, the varia- 

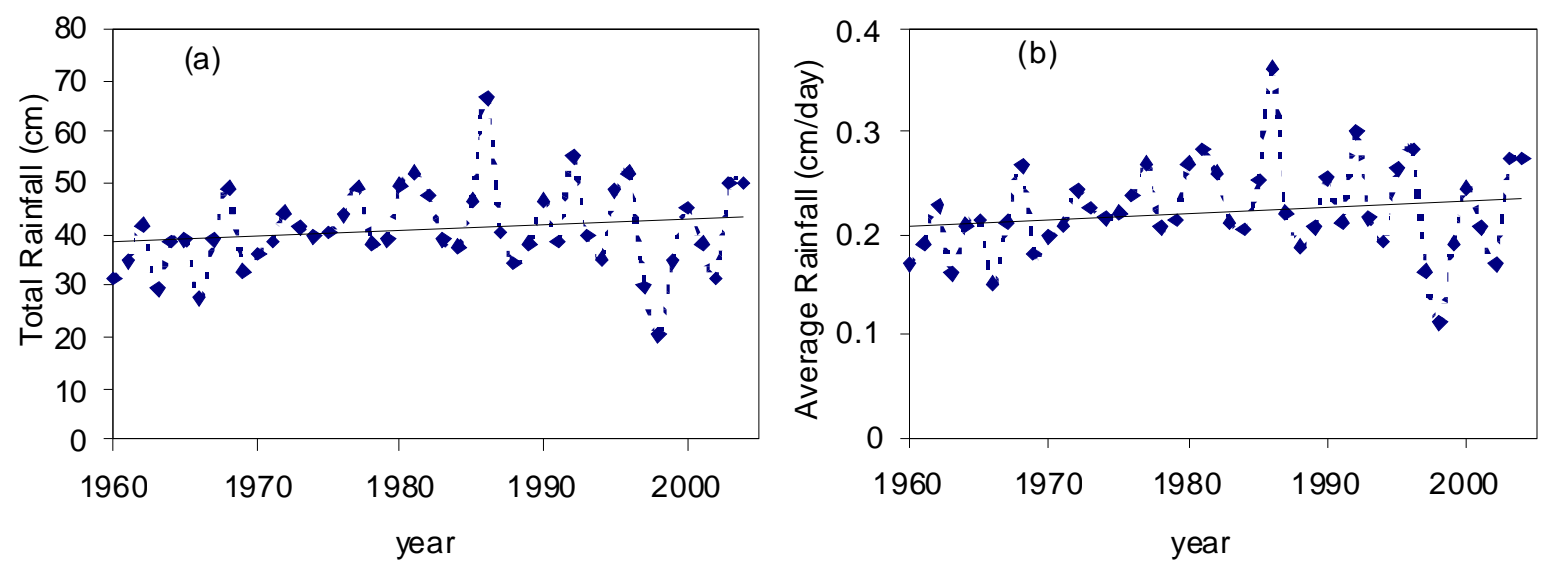

Figure 6. Growing season precipitation characteristics from 1960 to 2004 (a) Total Precipitation and (b) Average Daily Precipitation.

tion of precipitation from the previous 22 year period to the next has decreased. As with the soil moisture time series, the precipitation time series was also split up into the four decades of the 60's, 70's, 80's and 90's and analyzed. The means, the SD, and the COV of the four decades were calculated and are presented in Table 3.

Table 2. Some Statistical Characteristics of Precipitation during 1960-1981 and 1982-2003

\begin{tabular}{llll}
\hline Period & $1960-1981$ & $1982-2003$ & Increase \\
\hline Average & $0.217 \mathrm{~cm} /$ day & $0.227 \mathrm{~cm} /$ day & $4.6 \%$ \\
Standard Deviation & 0.140 & 0.126 & $-10 \%$ \\
COV & 0.643 & 0.557 & $-13.4 \%$ \\
\hline
\end{tabular}

Table 3. Some Statistical Characteristics of Precipitation (cm/day) during the 1960's, 1970's, 1980's and 1990's

\begin{tabular}{lllll}
\hline Period & $1960-1969$ & $1970-1979$ & $1980-1989$ & $1990-1999$ \\
\hline Average & 0.198 & 0.223 & 0.246 & 0.218 \\
Standard & 0.189 & 0.197 & 0.225 & 0.174 \\
$\begin{array}{l}\text { Deviation } \\
\text { COV }\end{array}$ & 0.958 & 0.884 & 0.916 & 0.799 \\
\hline
\end{tabular}

From the decadal analysis of precipitation it was found that, average growing season precipitation has increased $12.6 \%$ from the 1960 's to the 1970 's, and $10.3 \%$ from the 1970's to the 1980 's. There has been a $12.8 \%$ decrease in average growing season precipitation from the 1980's to the 1990's. However, since the 1960's to the 1990's the average growing season precipitation has increased by $10 \%$. There has been an increase in overall average growing season precipitation. The SD and the COV analyses show no obvious trend in daily growing season precipitation variations.

\subsection{Temperature}

The temperature characteristics of each individual growing season $(1960 \sim 2004)$ were examined. The average grow- ing season temperatures were calculated and are presented in Figure 7.

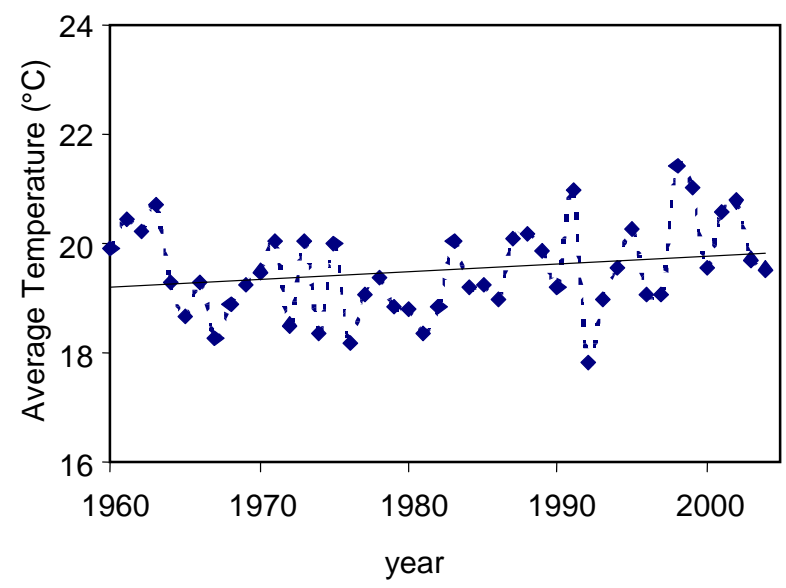

Figure 7. Average growing season temperature characteristics from 1960 to 2004 .

Table 4. Some Statistical Characteristics of the 1960-1981 and 1982-2003 Temperature $\left({ }^{\circ} \mathrm{C}\right)$

\begin{tabular}{llll}
\hline Period & $1960-1981$ & $1982-2003$ & Increase \\
\hline Average & 19.63 & 20.03 & $2 \%$ \\
Standard Deviation & 4.4 & 4.64 & $5.45 \%$ \\
Maximum & 25.83 & 26.08 & $0.8 \%$ \\
Minimum & 8.42 & 9.55 & $13.4 \%$ \\
\hline
\end{tabular}

The inter-annual growing season temperature fluctuations are evident from Figure 7. Linear regression analysis was carried out and the result is shown in Figure 7. As can be seen from the figure, there is a definite long-term increase in Toronto temperatures. The analysis determines that there has been a steady $1{ }^{\circ} \mathrm{C}$ increase in average growing season temperatures in the Toronto area from 1960 to 2004. The trend line analysis confirms global warming in south-western Ontario. The tempera- 

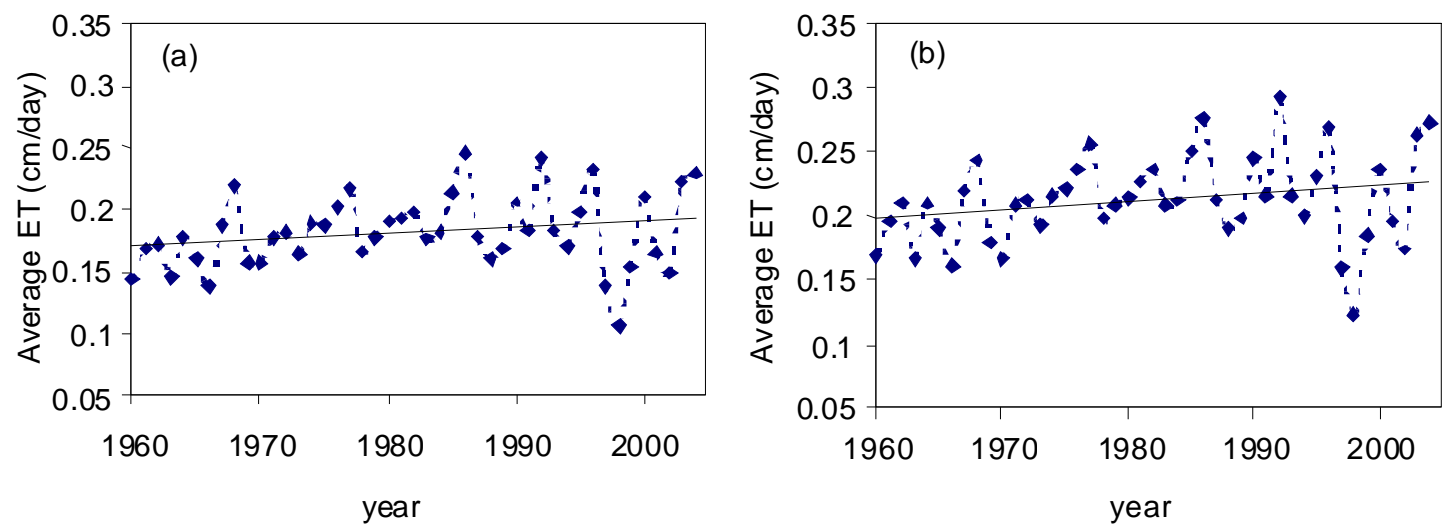

Figure 8. Model-simulated average growing season ET from 1960 to 2004 (a) scenario 1 and (b) scenario 2.

ture time series was split into the two sets of $1960 \sim 1981$ and $1982 \sim 2003$ as well. The means, the SD, the maximums and the minimums of the two sets were calculated and are presented in Table 4.

There has been a $2 \%$ increase in average growing season temperatures in the 22 year period of $1982 \sim 2003$ from that of $1960 \sim 1981$. Unlike precipitation, the variation of temperature from the earlier 22 year period to the next has also increased. An analysis of the maximum and minimum growing season temperatures indicates that there has been only a $1 \%$ increase in maximum growing season temperatures compared to a $13 \%$ increase in minimum growing season temperatures. As with the soil moisture and precipitation time series, the temperature time series was also divided up into the four decades of the 60's, 70's, 80's and 90's and analyzed. The means, the SD, the maximums and the minimums of the four decades were calculated and are presented in Table 5.

Table 5. Statistical Characteristics of Temperature $\left({ }^{\circ} \mathrm{C}\right)$ during the 1960's, 70's, 80's and 90's

\begin{tabular}{lllll}
\hline Period & $1960-69$ & $1970-79$ & $1980-89$ & $1990-99$ \\
\hline Average & 19.85 & 19.65 & 19.64 & 20.05 \\
Standard Deviation & 4.39 & 4.56 & 4.88 & 4.59 \\
Maximum & 26.11 & 26.42 & 27.09 & 26.69 \\
Minimum & 8.075 & 7.513 & 8.943 & 9.655 \\
\hline
\end{tabular}

From the decadal analysis of temperature it was found that, average growing season temperature had actually decreased $1 \%$ from the 1960 's to the 1970 's. Average growing season temperatures remained at $19.65^{\circ} \mathrm{C}$ throughout the 1970 's to the 1980 's. However, there has been a $2.1 \%$ increase in average growing season temperature from the 1980's to the 1990's. The SD and the COV analyses indicate that daily growing season temperature variations have increased but only very slightly. There has been a steady $1 \sim 2 \%$ increase in the average maximum growing season temperature, with the exception of the 1990's. There has been a steady $19 \sim 20 \%$ increase in the overall minimum growing season temperature, with the exception of the 1970's.

\subsection{Evapotranspiration}

To investigate the effect of global warming on ET and its relation with soil moisture, the ET characteristics of each individual growing season $(1960 \sim 2004)$ were analyzed. From the simulated daily ET for each growing season the average ET for that individual year was obtained. The resulting annual ET time series of the Toronto area as simulated by the continuous simulation model is shown in Figure 8. Linear regression analysis was carried out and it shows that even though there are significant inter-annual growing season ET variations, there has indeed been a steady increase from 1960 to 2004. The pattern of ET appears to be similar for both scenarios, however, with $30 \%$ imperviousness, scenario 2 has higher ET values. The SD of the simulated daily ET values was calculated for each individual growing season. The results are presented in Figure 9.

From the SD analysis we see that there has been a slight increase in the SD values from 1960 to 2004 which means that the day to day variation of ET has very steadily increased from the 1960's to 2004. Again, the pattern of scenarios 1 and 2 appear to be similar, however, scenario $2 \mathrm{SD}$ are higher than those of scenario 1. The range of SD of ET for scenario 1 falls within $0.1 \sim 0.25 \mathrm{~cm} /$ day while the range of SD of ET for scenario 2 falls within $0.1 \sim 0.3 \mathrm{~cm} /$ day. The COV of the simulated daily ET values have been calculated for each individual growing season. The results are presented in Figure 10.

From the COV analysis we see that there has been a very slight increase in the COV values from 1960 to 2004 which means that the day to day variation of ET has very steadily increased from the 1960's to 2004. Again, the pattern of scenarios 1 and 2 appear to be similar, however, the range of COV of ET for scenario 1 falls within $0.15 \sim 0.25 \mathrm{~cm} /$ day while the range of $\mathrm{COV}$ of $\mathrm{ET}$ for scenario 2 falls within $0.17 \sim 0.28$ $\mathrm{cm} /$ day.

\subsection{Influence of Precipitation and Temperature on Soil Moisture and ET}

The main focus of this study is to investigate the longterm characteristics of soil moisture and to investigate the in- 

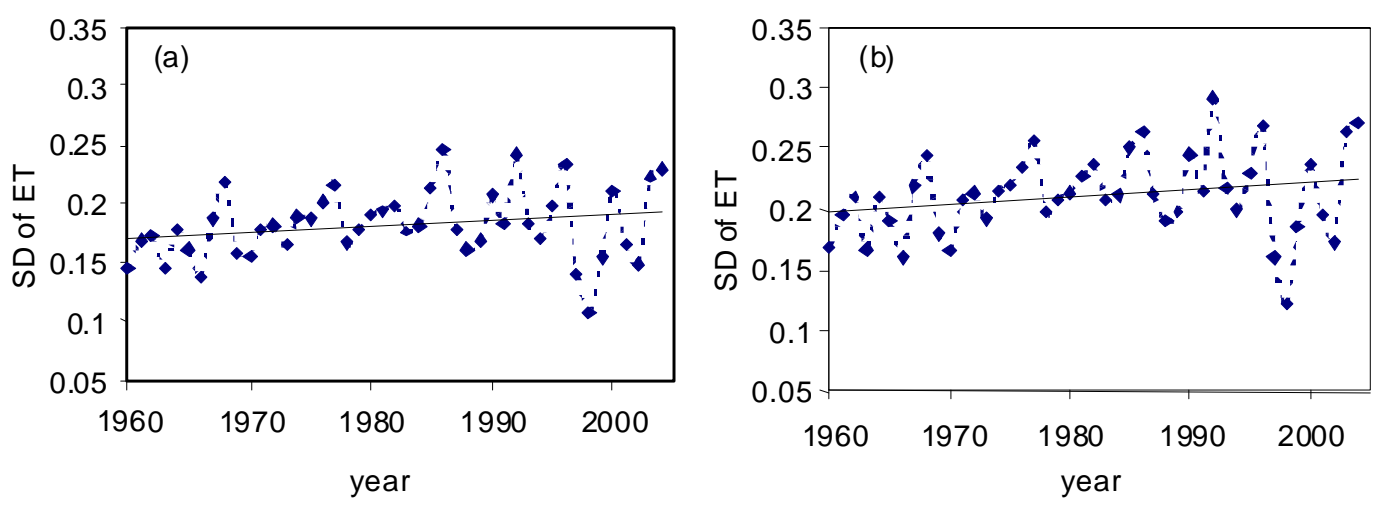

Figure 9. The standard deviations of the simulated growing season evapotranspiration from 1960 to 2004 (a) scenario 1 and (b) scenario 2.
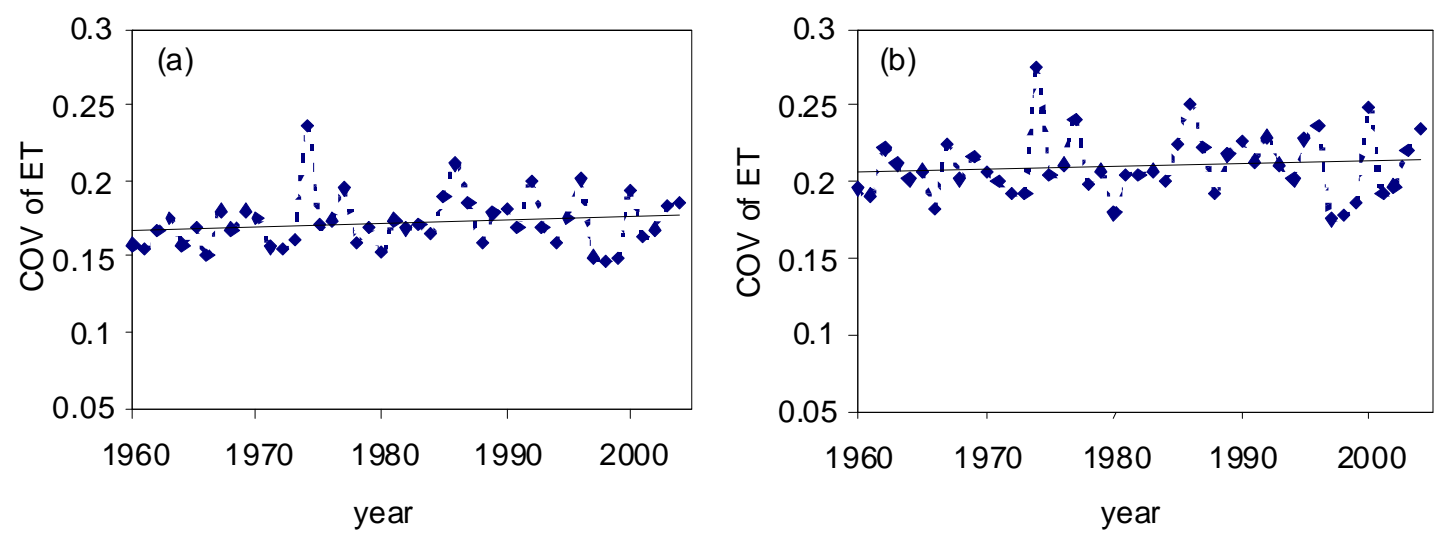

Figure 10. The coefficients of variation of the simulated growing season evapotranspiration from 1960 to 2004 (a) scenario 1 and (b) scenario 2 .

fluence of climate change on soil moisture availability. The daily averages were used to calculate monthly values for month to month comparison of daily precipitation, temperature, soil moisture and ET. It was found that in May and June, averaging over the entire 45 years $(1960 \sim 2004)$ for both scenarios 1 and 2, there is an increasing trend (not shown here due to space limitations) in all of the four parameters. Figure 11 shows the comparison for the month of July.

This comparison seems to reveal a direct relationship of soil moisture and ET with precipitation and an inverse relationship with temperature. This is because overall July precipitation, soil moisture and ET are deceasing from 1960 to 2004, whereas overall July temperatures are increasing. A similar relationship, i.e., decreasing soil moisture and ET with decreasing precipitation and increasing temperatures, was found for both scenarios for the month of August (not shown here to save space). However, for the following month of September there is an increasing trend (not shown here) in all the four parameters and for both scenarios, similar to May and June. For the month of October $(1960 \sim 2004)$ it was found that overall daily soil moisture and ET have increased with increasing precipitation but overall daily temperatures have decreased, as can be seen in Figure 12.
It is interesting to see that in contrast to the finding that growing season temperatures have on average increased throughout the 45-year period, in the month of October there is a general trend of decreasing temperatures. This may be an indication that the temperatures for the colder months have decreased overall. However, as the autumn and winter months are beyond the scope of this paper, no such trend can be verified. Figure 12 confirms the inverse relationship between temperature and soil moisture.

An analysis was carried out to find out if there is any direct link between the wettest and driest years with the hottest and coldest years, and the years registering the most and least soil moisture and ET. It was found that 1986 was the wettest year recording a total of $66.73 \mathrm{~cm}$ of precipitation, and 1998 was the driest year recording a total of $20.5 \mathrm{~cm}$ of precipitation during the growing season of May to October. However, the highest average growing season soil moisture of 0.32 and $0.297 \mathrm{~cm} /$ day was found to exist in 1992 for scenarios 1 and 2 respectively. The hottest year was found to be 1998, recording average growing season temperatures of $21.4^{\circ} \mathrm{C}$, which also is the year with the lowest average growing season soil moisture and ET for both scenarios 1 and 2. Similarly, the year with the highest average soil moisture, 1992, is the coolest growing 

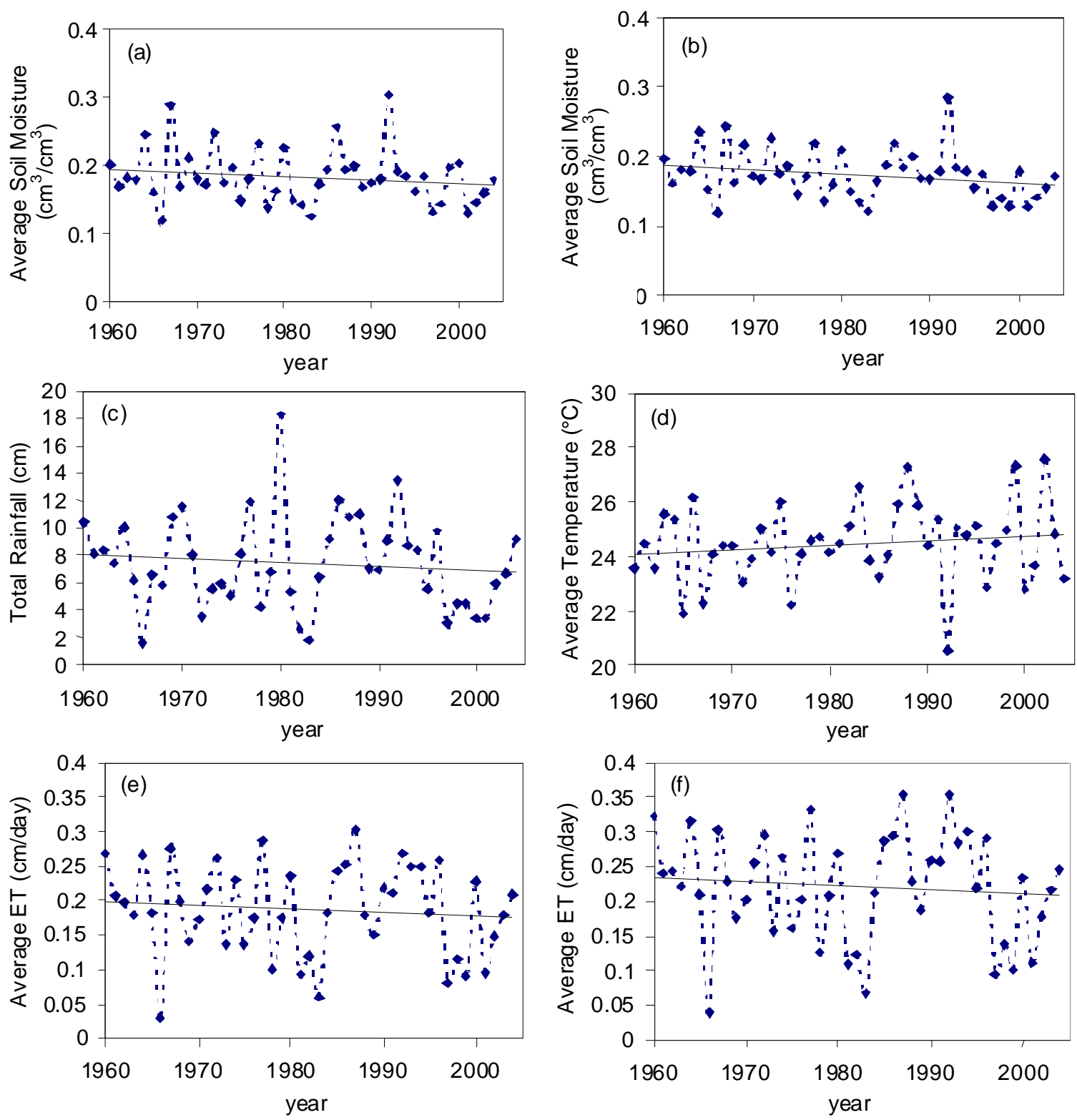

Figure 11. Daily July characteristics of the 45-year period of (a) soil moisture of scenario 1, (b) soil moisture of scenario 2, (c) total precipitation, (d) temperature, (e) ET of scenario 1, and (f) ET of scenario 2.

season year having an average temperature of $17.8^{\circ} \mathrm{C}$. A summary of this analysis has been tabulated in Table 6 . This analysis concludes that lowest soil moistures were found in the year with the highest temperatures and lowest precipitation. Whereas, the highest soil moistures were available in the year with the lowest temperatures and second highest precipitation. As for ET, the highest year coincides with the highest average growing season precipitation. The analysis found a strong relationship between precipitation and ET as contained in the results of the simplified continuous simulation model.

The results presented in Table 6 demonstrate that average growing season temperatures have a direct influence on average growing season soil moisture, more than precipitation; this is in contrast to the monthly comparisons presented in Figures 11 and 12. Similar to Sridhar et al. (2006), it was found that average growing season ET is less than average growing season precipitation. A direct measure of the relationship between the two time series is the Correlation Coefficient, $\rho_{x, y}$, calculated using Equation (2):

$\rho_{x . y}=\frac{\frac{1}{n} \sum_{j=1}^{n}\left(x_{j}-\mu_{x}\right)\left(y_{j}-\mu_{y}\right)}{\sigma_{x} \cdot \sigma_{y}},-1 \leq \rho_{x . y} \leq 1$

where:

$\mu=$ Average of the time series; 

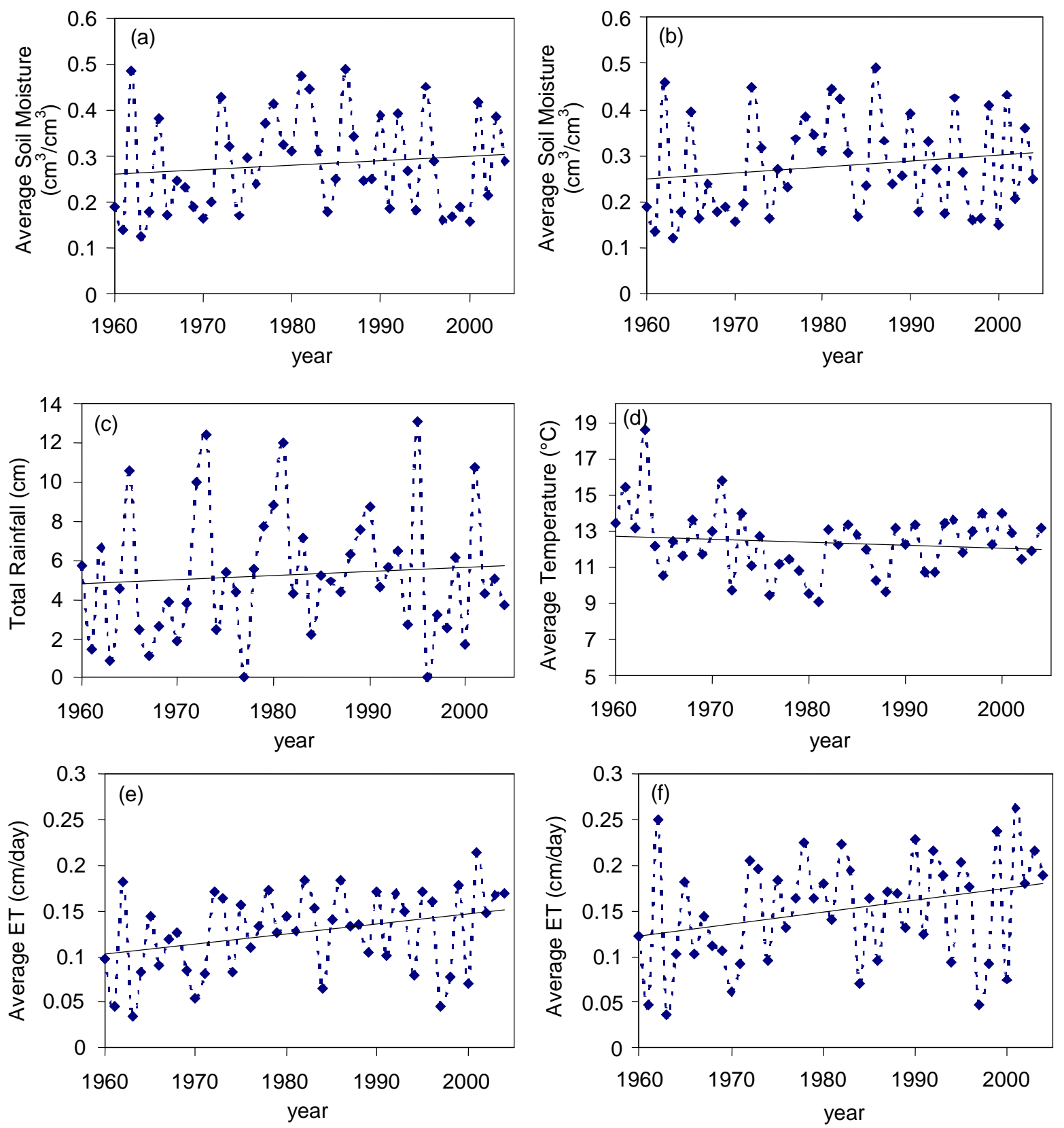

Figure 12. Daily October characteristics of the 45 year period (a) soil moisture of scenario 1, (b) soil moisture of scenario 2 , (c) total precipitation, (d) temperature, (e) ET of scenario 1, and (f) ET of scenario 2.

Table 6. A Summary of the Wettest, Driest, Coolest, and Hottest Growing Season Characteristics of the 45 year Period

\begin{tabular}{llllllll}
\hline Year & Aspect & $\begin{array}{l}\text { Total } \\
\text { Precipitation } \\
(\mathrm{cm})\end{array}$ & $\begin{array}{l}\text { Average } \\
\text { Temperature } \\
\left({ }^{\circ} \mathrm{C}\right)\end{array}$ & $\begin{array}{l}\text { Average Scenario 1 } \\
\text { Soil Moisture } \\
(\mathrm{cm} / \text { day })\end{array}$ & $\begin{array}{l}\text { Average Scenario 2 } \\
\text { Soil Moisture } \\
(\mathrm{cm} / \text { day })\end{array}$ & $\begin{array}{l}\text { Average } \\
\text { Scenario 1 ET } \\
(\mathrm{cm} / \text { day })\end{array}$ & $\begin{array}{l}\text { Average } \\
\text { Scenario 2 ET } \\
(\mathrm{cm} / \text { day })\end{array}$ \\
\hline 1986 & Wettest & 66.73 & 18.98 & 0.313 & 0.241 & 0.246 & 0.263 \\
1992 & Coolest & 55.03 & 17.83 & 0.320 & 0.297 & 0.242 & 0.292 \\
1998 & $\begin{array}{l}\text { Driest/ } \\
\text { Hottest }\end{array}$ & 20.54 & 21.41 & 0.149 & 0.146 & 0.107 & 0.123 \\
\hline
\end{tabular}


$\sigma=$ Standard Deviation of the time series;

$x=$ Variable 1;

$y=$ Variable 2; and

$n=$ Total number of observations in the time series.

A correlation coefficient value closer to positive 1 indicates a strong direct linear relationship, while a value closer to negative 1 indicates a strong inverse linear relationship. The values of correlation coefficients between different average growing season characteristics were obtained and are presented in Table 7. Table 7 shows that both soil moisture and ET have a strong positive correlation with precipitation, whereas both soil moisture and ET have a moderate negative correlation with temperature. Therefore the correlation coefficient analysis supports the earlier conclusion that the influence of precipitation is stronger than that of temperature on soil moisture and ET. Table 7 also shows that there is a strong linear relationship between ET and soil moisture, which is expected. A clearer understanding of the correlation analysis for scenario 1 is shown in Figure 13. Similar analysis was carried out for scenario 2 but is not shown here due to limitation of space.

Table 7. The Calculated Correlation Coefficients between Precipitation, Temperature, Soil Moisture and Evapotranspiration*

\begin{tabular}{llllll}
\hline Correlation & SM & SM & ET & ET & SM \\
Coefficient & vs. P & vs.T & vs. P & vs. T & vs. ET \\
\hline Scenario 1 & 0.904 & -0.577 & 0.930 & -0.512 & 0.832 \\
Scenario 2 & 0.827 & -0.547 & 0.903 & -0.500 & 0.808 \\
\hline
\end{tabular}

SM: Soil Moisture; P: Precipitation; T: Temperature; ET:

Evapotranspiration

\section{Conclusions}

With rising temperatures, increasing evapotranspiration will significantly impact vegetation, particularly in the agricultural community. Little attention however, has been paid to urban areas. Using 45-years of climate data and a vertical water balance model, this study investigated the growing season soil moisture characteristics of urban landuse with changing climate conditions. This study focused on urban grass lands in the largest urban area of Canada.

The climate data confirm both a gradual increase in longterm average temperatures and precipitation in south-western Ontario, Canada during the growing season of May to October. Since the 1960's, average growing season temperature and precipitation have increased by 2 and 4\% respectively. The study found that average growing season minimum temperatures have increased more than the average growing season maximum temperatures. This agrees with the findings of Wilby et al. (2002), Easterling et al. (2000, 1999), and Zhang et al. (2000). The monthly analyses showed an overall increase in May to September temperatures but an overall decrease in October temperatures. The monthly precipitation analyses also showed non-uniformity, with increasing precipitation in May, June, September and October and overall decreasing precipitation in July and August. An analysis of the model-simulated soil moisture values indicates that there has been a slight increase in soil moisture from 1960 to 2004, despite fluctuations from year to year. The model-simulated ET characteristics also exhibit similar patterns (i.e., even though there are significant inter-annual growing season ET variations, there has been an overall increase from 1960 to 2004).

The probability/frequency distributions give insight into the long-term soil moisture characteristics. All the pdfs generated showed the most likelihood of occurrence of volumetric soil moisture values near $0.2 \mathrm{~cm}^{3} / \mathrm{cm}^{3}$, the overall range being $0.15 \sim 0.35 \mathrm{~cm}^{3} / \mathrm{cm}^{3}$. The pdf comparison between the $1960 \sim$ 1981 and $1982 \sim 2003$ periods, each consisting of 22 years, clearly indicates that there has been a shift to the right, meaning the more likelihood of occurrence of higher soil moistures. The $1960 \sim 1981$ period pdf is unimodal, whereas, the $1982 \sim 2003$ period pdf is bimodal, showing a second peak at a higher soil moisture $\left(0.3 \mathrm{~cm}^{3} / \mathrm{cm}^{3}\right)$ value. The simulated soil moisture for the four decades of the 60's, 70's, 80's and 90's were separated, their pdfs were derived and compared. The comparison again shows that there has been a shift to the right The most significant difference between decades is that between the 60's and the 70's. The $1960 \sim 1969$ period pdf is unimodal, whereas the $1970 \sim 1979$ period pdf is clearly bimodal, with a second peak at a higher soil moisture value. The bimodal trend continues in the following decade of the 80's, and shows the probability of even higher soil moisture levels; between 0.35 and $0.4 \mathrm{~cm}^{3} / \mathrm{cm}^{3}$. The $1990 \sim 1999$ period pdf is, however, unimodal and shifts to the left from the 80 's pdf. 0.2 $\mathrm{cm}^{3} / \mathrm{cm}^{3}$ is the most common amount of soil moisture likely to exist throughout the growing season (May to October).

It was shown in this study that precipitation has a stronger control over soil moisture and ET in south-western Ontario, Canada. The monthly analyses showed that even in months (May, June, and September) where temperatures are increasing, both soil moisture and ET have also increased due to an overall precipitation increase. In contrast, there are months (July, August and October) where the inverse relationship is exhibited. The inverse relationship has also been supported by the correlation analysis and the coolest and driest year analysis. However, the average growing season analysis showed an overall increase in temperature, precipitation, soil moisture, and ET throughout the 45-year period. Therefore, it is concluded that even though temperatures have indeed increased throughout the 45 years analyzed, increasing precipitation has allowed the overall volumetric soil moisture availability to increase as well. This can be explained by the precipitation increase being higher than the ET increase. This observation has interesting implications on urban lawn care. With higher temperatures comes the general anticipation that there will be a need for increased lawn watering. The findings from this study shows that water saving practices should be continued out in south-western Ontario, Canada. More frequent watering of urban grass lands in the Toronto area is perhaps not necessary as the climate continues to change in the same direction.

Direct measurement of soil moisture is costly and it will take a long time to accumulate sufficient data for statistical analysis. This is especially true for south-western Ontario, Ca- 

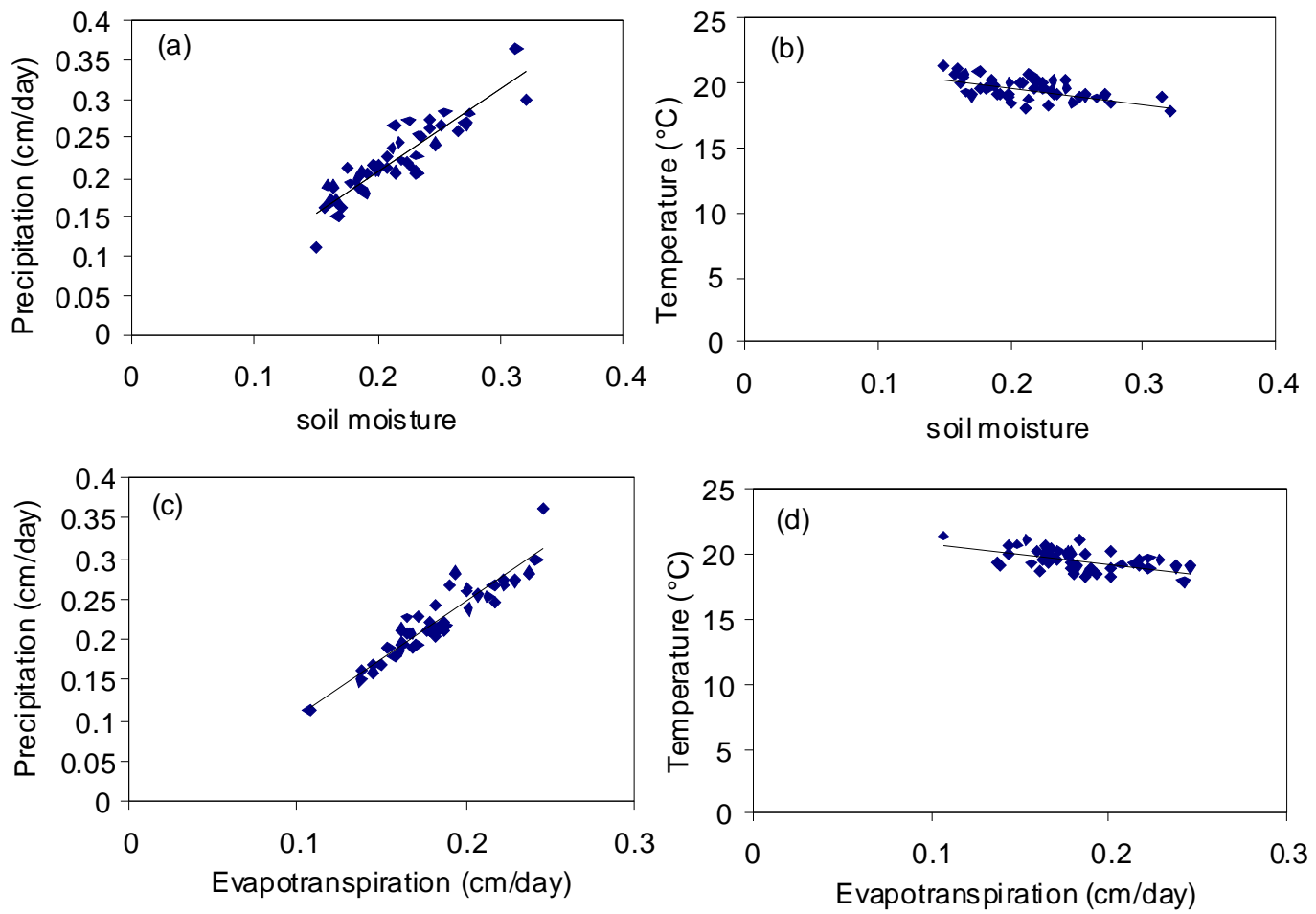

Figure 13. Correlation of average growing season characteristics from scenario 1: (a) soil moisture and precipitation, (b) soil moisture and temperature, (c) evapotranspiration and precipitation, and (d) evapotranspiration and temperature.

nada, where long-term soil moisture data is not available. In the absence of long-term observed soil moisture data, simplified continuous simulation models are excellent tools in analyzing the general soil moisture characteristics for climatesoil-vegetation systems. What is presented in this paper is an example of this type of analysis.

Acknowledgments. The authors are grateful to Ms. Sandy Radecki, Ontario Climate Centre, Toronto, Ontario, Canada for providing the climate data. The authors would also like to acknowledge the support from the Natural Sciences and Engineering Research Council of Canada.

\section{References}

Angel, J.R. and Huff, F.A. (1997). Changes in Heavy Rainfall in Midwestern United States, J. Water Resour. Plann. Manage., 123(4),246-249, doi:10.1061/(ASCE)0733-9496(1997)123:4(246).

Changnon, S.A. and Wescott, N. (2002). Heavy Rainstorms in Chicago: Increasing Frequency, Altered Impacts, and Future Implications, J. Am. Water Resour. Assoc., 38(5), 1467-1475, doi:10.1111/j. 1752-1688.2002.tb04359.x.

Chen, B. (2007). Climate Change and Pesticide Loss in Watershed Systems: A Simulation Modeling Study, J. Env. Inform., 10(2), 55 67, doi:10.3808/jei.200700100.

Chen, M., Dickinson, R.E., Zeng, X. and Hahmann, A.N. (1996). Comparison of Precipitation Observed over the Contiguous United States to that by a Climate Model, Bull. Am. Meteorol. Soc., 9, 2233-2249.
Chow, V.T., Maidment, D.V. and Mays, L.W. (1988). Applied Hydrology, McGraw-Hill Inc.

Dang, H., Gillett, N.P., Weaver, A.J. and Zwiers, F.W. (2007). Climate Change Detection over Different Land Surface Vegetation Classes, Int. J. Climatol., 27, 211-220, doi:10.1002/joc.1397.

Douville, H. and Chauvin, F. (2000). Relevance of Soil Moisture for Seasonal Climate Predictions: A Preliminary Study, Clim. Dyn., 16, 719-736.

Easterling, D.R., Meehl, G.A., Parmesan, C., Changnon, S.A., Karl, T.R. and Mearns, L.O. (2000). Climate Extremes: Observations, Modeling, and Impacts, Science, 289, 2068-2074, doi:10.1126/sci ence.289.5487.2068.

Easterling, D.R., Evans, J.L., Groisman, Karl, T.R., Kunkel, K.E. and Ambenje, P. (1999). Observed Variability and Trends in Extreme Climate Events: A Brief Review, Bull. Am. Meteorol. Soc., 81, 417-425, doi:10.1175/1520-0477(2000)081<0417:OVATIE >2.3.C $\mathrm{O} ; 2$.

Entin, J.K., Robock, A., Vinnikov, K.Y., Zabelin, V., Liu, S.X., Namkhai, A. and Adyasuren, T. (1999). Evaluation of the Global Soil Wetness Project Soil Moisture Simulations, Meteorological Society of Japan, 77(1), 183-198.

Fowler, H.J. and Kilsby, C.G. (2003). Implications of Changes in Seasonal and Annual Extreme Rainfall, Geophys. Res. Lett., 30 (13), 1720, doi:10.1029/2003GL017327, 2003.

Groisman, P.Y., Knight, R.W., Easterling, D.R., Karl, T.R., Hegerl, G.C. and Razuvaev, V.N. (2005). Trends of Intense Precipitation in the Climate Record, J. Clim., 9(9), 1326-1350, doi: 10.1175/JCLI3 339.1 .

Groisman, P.Y. and Easterling, D.R. (1994). Variability and Trends of 
Total Precipitation and Snowfall over the United States and Canada, J. Clim., 7(1), 184-205, doi:10.1175/1520-0442(1994)007 $<0184$ :VATOTP $>2.0 . C O ; 2$.

Guo, Z. and Dirmeyer, P.A. (2006). Evaluation of the Second Global Soil Wetness Project Soil Moisture Simulations: 1. Intermodel Comparison, J. Geophys. Res., 111(D22), Art. No. D22SO2, D22S 02, doi:10.1029/2006JD007233.

Guo, Z., Dirmeyer, P.A., Hu, Z.Z., Gao, X. and Zhao, M. (2006). Evaluation of the Second Global Soil Wetness Project Soil Moisture Simulations: 2. Sensitivity to external Meteorological Forcing, J. Geophys. Res., 111(D22), Art. No. D22SO3, doi:10.1029/2 006JD007845.

Hamlet, A.F., Mote, P.W., Clark, M.P. and Lettenmaier, D.P. (2007) Twentieth-Century Trends in Runoff, Evapotranspiration, and Soil Moisture in the Western United States, Bull. Am. Meteorol. Soc., 20, 1468-1486.

Hirabayashi, Y., Kanae, S., Struthers, I. and Oki, T. (2005). A 100Year (1901-2000) Global Retrospective Estimation of the Terrestrial Water Cycle, J. Geophys. Res., 110(D19), Art. No. 19101, doi: 10.1029/2004JD005492.

Hirabayashi, Y., Oki, T., Kanae, S. and Musiake, K. (2003). Application of Satellite-Derived Soil Moisture Data to Simulating Seasonal Precipitation by a Simple Soil Moisture Transfer Model, Bull. Am. Meteorol. Soc., 4, 929-943.

Hoffman, D.W. and Richards, N.R. (1953). Soil Survey of Peel County. Report No.18 of the Ontario Soil Survey, Ontario Ministry of Agriculture and Food, Guelph, Ontario, Canada.

Huang, J., van den Dool, H.M. and Georgakakos, K.P. (1996). Analysis of Model-Calculated Soil Moisture over the United States (1931-1993) and Applications to Long-Range Temperatures Forecasts, J. Clim., 9, 1305-1362.

Lewis, J.E. (1989). Climatic Change and its Effects on Water Resources for Canada: A Review, Can. Water Resourc. J., 14(1), 35 55 .

Karl, T.R., Knight, R.W. and Plummer, N. (1995). Trends in HighFrequency Climate Variability in the Twentieth Century, Nature, 377, 217-220, doi:10.1038/377217a0.

Kunkel, K.E., Easterling, D.R., Redmond, K. and Hubbard, K. (2003). Temporal Variations of Extremes Precipitation Events in the United States: 1985-2000, Geophys. Res. Lett., 30(17), 1900, doi:10.1 029/2003GL018052.

Kunkel, K.E., Andsager, K. and Easterling, D.R. (1999). Long-Term Trends in Extreme Precipitation Events over the Conterminous United States and Canada, J. Clim., 12, 2515-2527.

Liang, X. and Lettenmaier, D.P. (1994). A Simple Hydrologically Based Model of Land Surface Water and Energy Fluxes for General Circulation Models, J. Geophys. Res., 99(D7), 14,415-14,428, doi:10.1029/94JD00483.

Mahmood, R. and Hubbard, K.G. (2004). An Analysis of Simulated Long-Term Soil Moisture Data for Three Land Uses under Contrasting Hydroclimatic Conditions in the Northern Great Plains, $J$. Hydrometeorol., 5, 160-179, doi:10.1175/1525-7541(2004)005<0 160:AAOSLS $>2.0 . \mathrm{CO} ; 2$.

Mahmood, R. and Hubbard, K.G. (2003). Simulating Sensitivity of Soil Moisture and Evapotranspiration under Heterogeneous Soils and Land Uses, J. Hydrol., 280, 72-90, doi:10.1016/S0022-1694 (03)00183-5.

Manobavan, M., Lucas, N.S., Boyd, D.S. and Petford, N. (2003). The Sensitivity and Response of Terrestrial South American Vegetation to Interannual Climatic Variability Induced by the ENSO, J. Env. Inform., 2(2), 1-10, doi:10.3808/jei.200300018.

Maurer, E.P., Wood, A.W., Adam, J.C., Lettenmaier, D.P. and Nijssen, B. (2002). A Long-Term Hydrologically Based Dataset of Land Surface Fluxes and States for the Conterminous United States, J. Clim., 15(22), 3237-3251.
Mavromatis, T. and Jones, R.D. (1999). Evaluation of HADCM2 and Direct use of Daily GCM Data in Impact Assessment Studies, Climate Change, 41, 583-614.

Mintz, Y. and Walker, G.K. (1993). Global Fields of Soil Moisture and Land Surface Evapotranspiration Derived from Observed Precipitation and Surface Air Temperatures, J. Appl. Meteorol., 32, 1305-1334, doi:10.1175/1520-0450(1993)032<1305:GFOSMA $>2$. $0 . \mathrm{CO} ; 2$.

Mitchell, J.F.B. and Warrilow, D.A. (1987). Summer Dryness in Northern Mid-Latitudes due to Increased CO2, Nature, 330, 238-240, doi: $10.1038 / 330238 \mathrm{a} 0$.

Nishat, S., Guo, Y. and Baetz, B.W. (2007). Development of a Simplified Continuous Simulation Model for Investigating Long-term Soil Moisture Fluctuations, Agric. Water Manage., 92, 53-63, doi:10.1016/j.agwat.2007.04.012.

Nemec, J. and Schaake, J. (1982). Sensitivity of Water Resources Systems to Climate Variation, Hydrol. Sci. J., 27(3), 327-343.

Osborn, T.J., Hulme, M., Jones, P.D. and Basnett, T.A. (2000). Observed Trends in the Daily Intensity of United Kingdom Precipitation, Int. J. Climatol., 20, 347-364.

Poporato, A., Daly, E. and Rodriguez-Iturbe, I. (2004). Soil Water Balance and Ecosystem Response to Climate Change, Am. Nat., 164(5), 625-632.

Robock, A., Vinnikov, K.Y., Srinivasan, G., Hollinger, S.E., Entin, J.K., Speranskaya, N.A., Liu, S.X. and Namkhai, A. (2000). The Global Soil Moisture Data Bank, Global Planet. Change, 19, 181208.

Robock, A., Schlosser C.A., Vinnikov, K.Y., Speranskaya, N.A., Entin, J.K. and Qiu, S. (1998). Evaluation of the AMIP Soil Moisture Simulations, Bull. Am. Meteorol. Soc., 81(6), 1281-1299, doi: 10.1016/S0921-8181(98)00047-2.

Smit, B. (1989). Implications of Climate Change for Agriculture and Land Use, Report of the First U.S.-Canada Symposium on Climate Change on the Great Lake Basin, Joint Report No. 1, 188-193.

Sridhar, V., Hubbard, K.G. and Wedin, D.A. (2006). Assessment of Soil Moisture Dynamics of the Nebraska Sandhills Using LongTerm Measurements and a Hydrology Model, J. Irrig. Drain. Eng., 132(5), 463-473, doi:10.1061/(ASCE)0733-9437(2006)132:5(463).

Srinivasan, G., Robock, A., Entin, J.K., Luo, L., Vinnikov, K.Y., Viterbo, P. and Participating AMIP Modeling Groups, (2000). Soil Moisture Simulations in Revised AMIP Models. Journal of Geophysical Research. 105(D21), 26,635-26,644.

Stone, D.A., Weaver, A.J. and Zwiers, F.W. (2000). Trends in Canadian Precipitation Intensity, Atmosphere-Ocean, 38(2), 321-347.

Tong, S.T.Y., Liu, A.J. and Goodrich, J.A. (2007). Climate Change Impacts on Nutrient and Sediment Loads in a Midwestern Agricultural Watershed, J. Env. Inform., 9(1), 8-28, doi:10.3808/jei.20070 0084

Trenberth, K.E. (1999). Conceptual Framework for Changes of Extremes of the Hydrological Cycle with Climate Change, Climate Change, 42, 327-339.

Varanou, E., Gkouvatsou, E., Baltas, E. and Mimikou, M. (2002). Quantity and Quality integrated Catchment Modeling under Climate Change with use of Soil and Water Assessment Tool Model, $J$. Hydrol. Eng., 7(3), 228-244, doi:10.1061/(ASCE)1084-0699(2002) 7:3(228).

Viessman, W.J. and Lewis, G.L. (2003). Introduction to Hydrology (5th Edition), Addison-Wesley Publishers Inc.

Vinnikov, K.Y. and Grody, N.C. (2003). Global Warming Trend of Mean Tropospheric Temperatures Observed by Satellites, Science, 302, 269-272, doi:10.1126/science. 1087910 .

Wang, W. and Kumar, A. (1998). A GCM Assessment of Atmospheric Seasonal Predictability Associated with soil Moisture Anomalies over North America, J. Geophys. Res., 103(D22), 28,637-28,646.

Wilby, R.L., Dawson, C.W. and Barrow, E.M. (2002). SDM-A Deci- 
sion Support Tool for the Assessment of Regional Climate Change Impacts, Environmental Modeling and Software, 17, 147-159, doi 10.1016/S1364-8152(01)00060-3.

Whitfield, P.H. and Cannon, A.J. (2000). Recent Variations in Climate and Hydrology in Canada, Can. Water Resourc. J., 25(1), 1965.

Whittrock, V. and Ripley, E.A. (1999). The Predictability of Autumn Soil Moisture Levels on the Canadian Prairies, Int. J. Climatol., 19, 271-289,

doi:10.1002/(SICI)1097-0088(19990315)19:3<271::AID-

JOC362>3.0.CO;2-G.
Zhang, X., Vincent, L.A., Hogg, W.D. and Niitsoo, A. (2000). Temperature and Precipitation Trends in Canada During the 20th Century, Canadian Meteorological and Oceanographic Society, 38(3), 395-429.

Zhang, C., Dazlich, D.A. and Randall, D.A. (1999). Simulations of Soil Moisture and Surface Water Balance Using Simple Biosphere Model 2, Meteorological Society of Japan, 77(1), 217-234.

Zwiers, F.W. and Kharin, V.V. (1998). Changes in the Extremes of the Climate Simulated by CCC GCM2 under CO2 Doubling, J. Clim., 11(22), 2200-2222, doi:10.1175/1520-0442(1998)011<2200:CITE OT>2.0.CO;2. 